\title{
Kulturarv - et begreb til forhandling
}

\author{
Beate Knuth Federspiel*
}

Title: Cultural heritage - a concept up for negotiation.

Abstract: The international organisations active in the field of cultural conservation represent the normative framework for the protection of culture and heritage. Within this administrative and legal system, ideas about the overall meaning of the cultural heritage preservation concept are created and disseminated, and these have implications for museums' obligations (collection, recording, conservation, research and communication), which collectively can be seen as society's overall effort to preserve cultural heritage.

The subject of this article is to examine how cultural conservation efforts shift focus in step with changes in society's overall understanding of the concept of cultural heritage which by nature is the object of these conservation efforts. The most recent UNESCO conventions on culture (The Convention for the Safeguarding of Intangible Cultural Heritage and The Convention for the Protection and Promotion of the Diversity of Cultural Expressions) testify to a growing appreciation of the value of this overall concept, focusing on people, right down to individual level - whereas focus was previously on national unity and a shared "story" as the identification markers. The situation may seem especially justified by the distinction between tangible and intangible heritage, in which the intangible is increasingly taken into account. This article highlights key concepts and the continuing debate about their importance in the normative system. The emphasis is on the increasing value attributed to the concept of heritage, and the distinction between tangible and intangible heritage. Against this background, possible consequences for the basic conservation effort are discussed, because this is the foundation of the fundamental idea of what a museum is, as well as justifying the normative system in the field of culture.

Key words: Cultural heritage, intangible cultural heritage, cultural conservation, preservation theory, cultural heritage ecology. 


\section{BAGGRUND}

Sociologiske og historiske studier har i de seneste årtier haft et særligt fokus på betydningen af kulturarv som en konstituerende faktor i samfundet (Hall 1997, Turtinen 2006, Jensen 2008, Labadi and Long 2010). Den erkendelse afspejles også i det internationale juridiske og administrative system, som beskytter kulturarv. De internationale organisationer på kulturområdet, med UNESCO i spidsen, udgør den normative ramme for kulturbevaring. Inden for den ramme skabes og udbredes forestillinger om kulturarvsbegrebets betydning og rækkevidde, og om globale problemstillinger, der knytter sig til begrebet. De normative tekster, der styrer teori og praksis på bevaringsområdet, viser, at kulturarv er et begreb, som i høj grad er til forhandling. Artiklen analyserer nogle eksempler på nutidige tekster inden for lovgivning og forvaltning for at underbygge den påstand. Fokus er på begrebet kulturarv og den fortsatte forhandling om dets betydning med særlig vægt på den værditilskrivning til begrebet, som især sker i kraft af distinktionen mellem materiel og immateriel kulturarv og det øgede fokus på det immaterielle.

Det er ikke i sig selv nyt at dele kulturarv op i kategorier, som passer til de herskende forestillinger om, hvad kulturarv er: de tidlige normative instrumenter på området skelnede mellem property over for heritage, og mellem movable over for immovable (Stanley-Price 2003). Disse kategoriseringer er eksempler på, at der siden 1950'erne i det normative system har været etableret nogle begrebsmæssige distinktioner, som fik betydning både for institutionaliseringen af området, og for uddannelserne, som især blev etableret fra 1950'erne og frem i en række faglige specialiseringer med hver deres uddannelsesprogrammer (arkitektur restaurering, konservering og restaurering af kunstværker, af arkæologiske og kulturhistoriske genstande, og af arkivalske og fotografiske materialer). De begrebsmæssige og faglige skel har i tidens løb ikke altid virket fremmende for tværfaglige eller tværinstitutionelle bevaringsbestræbelser. Tendensen til at ophæve de begrebsmæssige distinktioner er tydelig i de normative instrumenter i det seneste årti. De diskussioner, de rejser om bevaringens teori og praksis, må forventes at få betydning for, hvordan vi indsamler, bevarer, forsker $\mathrm{i}$ og formidler kulturarv.

I den engelske sprogbrug sidestilles intangible heritage ofte med living heritage, og denne opmærksomhed på levende kulturarv, som senest har udmøntet sig i et stærkt instrument i form af en ny UNESCO konvention om immateriel kulturarv, nødvendiggør en gentænkning af nogle af de grundlæggende incitamenter for at bevare, som på internationalt plan er indskrevet i definitionen af museet. Det analytiske blik er i denne sammenhæng konservatorens, hvilket betyder, at refleksionerne har udgangspunkt i bestræbelsen på den fysiske bevaring af genstande og materialer.

Indledningsvis er det nærliggende at se på, hvordan begrebet kulturarv forstås i det forvaltnings- og lovgivningsmæssige system. For at gøre en sådan analyse mere nærværende vil jeg tage udgangspunkt i den danske forvaltning ved dels at se på Kulturarvsstyrelsens ${ }^{2}$ definition af begrebet kulturarv, og dels på brugen af begrebet i et par af Kulturarvsstyrelsens tekster, som efter strukturreformen i 2005, sigtede på at skærpe kommunernes opmærksomhed på kulturarv. Dette er et område, hvor kommunerne som planlægningsmyndighed blev den største forvalter af kulturhistoriske værdier efter reformen. ${ }^{3}$ Derfra vil perspekti- 
6 vet bredes ud til det internationale system af kulturbevarende instrumenter, som dansk forvaltning og lovgivning på kulturområdet refererer til i den udstrækning, Danmark har ratificeret UNESCOs konventioner på området. ${ }^{4}$ Progressionen $\mathrm{i}$ analysen vil således tage udgangspunkt i nutidens forestillinger om begrebet og derfra belyse forudsætningerne bagud i tid.

\section{DEFINITIONER AF KULTURARV}

Det ligger i sagens natur, at det normative system, som sætter rammer for, at noget kan beskyttes, tilstræber præcise definitioner af, hvad retningslinierne retter sig imod (det normative udstikker retningslinier for, hvad der bør gøres i forhold til det område, normsætningen retter sig imod). Den forudsætning skaber lejlighedsvise paradokser. Dette kan illustreres med et citat fra Laurajane Smith, professor i Heritage Studies ved York Universitet. Smith udfordrer i bogen Uses of Heritage (Smith 2006) forestillingen om kulturarv som et veldefineret og selvforklarende begreb, hvis værdi er selvindlysende og begrundelse nok for, at kulturarv skal bevares: "There is, really, no such thing as heritage" (Smith 2006: 11). Dermed anfægter hun selve idégrundlaget for det normative system, som beskytter kulturarv.

Hvordan forstås begrebet kulturarv i den danske forvaltning af området, som varetages af Kulturarvsstyrelsen? Styrelsens definition af kulturarv lyder sådan:

Den danske kulturarv omfatter alt, hvad mennesket har efterladt sig gennem tiderne: strukturer, konstruktioner, bygningsgrupper, bopladser, grave og gravpladser, flytbare genstande og monumenter og den sammenhæng, hvori disse spor er anbragt. Det vil sige hele samfundsudviklingen frem til i dag. I Danmark sondrer vi mellem den faste kulturarv (bygninger, broer, gravhøje), den løse kulturarv (genstande, som ofte opbevares på museer, i arkiver eller på biblioteker) og den immaterielle kulturarv (for eksempel egnsretter, folkeviser eller Bournonville-balletten). (http:// www. kulturarv.dk/om-os/om-kulturarvsstyrelsen/hvad-er-kulturarv/)

Kulturarvsstyrelsens vision er formuleret som følger:

Vores vision er at udvikle kulturarvens mulighed for at blive en aktiv ressource i forhold til samfundsudviklingen. Det gør vi bl.a. ved at arbejde for at gøre kulturarven mere synlig og ved at indgå i dialog og partnerskaber med forskellige interessenter. (http:// www.kulturarv.dk/om-os/)

Denne overordnede definition og vision lægger sig, ikke overraskende, tæt op ad definitionerne af kulturarv i de internationale konventioner, som der også henvises til på styrelsens hjemmeside. De retningsledende tekster i forhold til kommunernes nye forvaltningsforpligtelser efter 2005 tilstræber en instrumentalisering af begrebet. For at vise dette, har jeg valgt citater fra to tekster med 5 års mellemrum. De afspejler, at der i systemet er en vis usikkerhed over for håndteringen af begrebet. Citaterne stammer dels fra en undersøgelse, som Kulturarvsstyrelsen og Realdania lavede i 2005 om danskernes holdninger til kulturarv (Kuas 2005), og dels fra en senere publikation med samme sigte: Kommune - kend din kulturarv (Kuas 2010).

Kulturarven er med til at gøre vores fælles historie konkret, og kulturarven giver den enkelte en forståelse af identitet og ophav... (Kuas 2005: 9).

Jeg kunne have valgt andre lignende eksemp- 
ler fra denne rapport; fælles for dem er (udover bøjningsformen), at det forbliver lidt forblommet, hvad det er, der tales om i den bestemte entalsform, der antyder, at det handler om noget, enhver ved, hvad er, altså noget selvforklarende. Det fremgår, at der er tale om noget, som gør historien konkret, som det siges. Der er tale om en materialisering af en fortelling, som kan "give en forståelse af identitet og ophav"- kulturarv(en) kan altså bruges til noget. Det er, uden at det er direkte udtalt, de materielle, historiske og æxtetiske aspekter af begrebet, som er centrale her. 5 år senere er forståelsen af begrebet tilsyneladende blevet meget bredere:

For mange er kulturarven diffus og svær at bruge som afsæt i konkrete udviklingsplaner. Men kulturarven er autentisk, den er bundet til konkrete steder, og sporene vidner om det levede liv. (Kuas 2010: 2-3).

Selv om begrebet stadig optræder i bestemt entalsform, er forståelsen bredt ud til at omfatte noget så uhåndgribeligt som steder og det levede liv. Desuden forbindes begrebet med udvikling i overensstemmelse med styrelsens formulerede vision. Her er vi klart ovre i de immaterielle aspekter af begrebet og en meget inkluderende forståelse af, hvad det kan dække. Hvordan hænger denne begrebslige udvikling sammen med de forestillinger, som i løbet af de seneste tre årtier har forandret de internationale instrumenter på kulturbevaringsområdet?

\section{DEN SOCIO-KULTURELLE DIMENSION}

Det var i Burra Charteret fra 1979, at begrebet places of cultural significance blev introduceret. Burra Charteret, som er formuleret af den australske afdeling af ICOMOS, marke- rer et vendepunkt i erkendelsen af kulturarvens socio-kulturelle dimension, som ikke nødvendigvis er betinget af noget materielt $\mathrm{i}$ form af monumenter, kunstværker eller genstande. Kulturarvens sociale værdi defineres i Burra Charteret som "...the qualities for which a place has become a focus of spiritual, political, national or other cultural sentiment...".5 Den definition passer fint til Kulturarvsstyrelsens initiativ med at udpege kulturarvskommuner, hvor det ikke (nødvendigvis) er historiske eller æstetiske monumenter, der fokuseres på, men netop et steds socio-kulturelle kvaliteter (Kuas 2007). Der tales i citatet også om, at kulturarven repræsenterer noget autentisk. Klogt nok er der ingen forsøg på at præcisere, hvori autenticiteten består. Det er også en meget lang diskussion, som især blev intens fra midten af 1970'erne i forhold til Verdensarvkonventionen. Diskussionen nåede en foreløbig konklusion med Nara dokumentet i $1994,{ }^{6}$ hvor der defineres en ny forståelse af autenticitetsbegrebet, som indtil da havde været associeret med materiel oprindelighed. Nara dokumentet breder forestillingen om autenticitet ud til også at omfatte de ikke materielle aspekter af den kulturelle arv, samtidig med at der lægges vægt på respekten for kulturel forskellighed, som efterfølgende blev et omdrejningspunkt i den videre betydningstilskrivning til begrebet kulturarv.

\section{KULTURARV - EN FLYDENDE BETEGNER}

For at kunne forstå den internationale kulturarvsdiskurs, som ligger bag disse formuleringer og denne begrebsbrug i den danske forvaltning, kan man med fordel bruge lidt teori til at analysere med:

En diskursteoretiker ville kalde begrebet kulturarv for en flydende betegner. Flydende 
8 betegnere er begreber, der i særlig grad er åbne for betydningstilskrivninger, og om hvilke der foregår en stadig kamp mellem forskellige interesser om at indholds-udfylde. Som denne artikel allerede har vist et par eksempler på, afspejler det danske administrative system denne bestræbelse på at fylde indhold i begrebet. $\mathrm{Og}$ når man dykker længere ned i materien, viser det sig, at der under kulturarvsbegrebet ligger en række konflikter, som til stadighed udspilles i og uden for systemet, og som betyder, at begrebet er under stadig forandring og er genstand for løbende forhandlinger om dets betydning og rækkevidde. Det er en af forklaringerne på, at den internationale lovgivning på kulturarvsområdet stadig ekspanderer. Der er en mængde interesser på spil: politiske, ideologiske, økonomiske og nationale. Den svenske etnolog Jan Turtinen har i sin doktordisputats fra 2006 fra Stockholm Universitet påvist de underliggende konflikter med afgørende indflydelse på, hvordan kulturarv forstås og især bruges i nutidens samfund. Han siger blandt andet:

... kulturarv är ett verktyg för intervention och... handlar om att organisera mångfald och få menniskor till att se på sig själva och sina traditioner på särskilda sätt för att derigenom kunna styra dem. (Turtinen 2006: 28).

Turtinen påviser med en række eksempler, at forvaltning og lovgivning, nationalt og internationalt, afspejler samtidens kulturelle og sociale værdier og globale problemstillinger, og at kulturarv indtager en stadig mere central rolle som en konstituerende faktor i nutidens samfund. Han mener altså, at kulturarv gør noget ved nutidens samfund, og ligefrem kan bruges som en styrende faktor. Passer det nu også?

\section{KULTURARVSDISKURSER}

Nogle af de vigtigste stikord, der knytter sig til forståelsen, eller indholdsudfyldelsen af kulturarvsbegrebet i det normative system, lader sig nemt udpege: Verdensarv, kulturel diversitet, kulturel pluralisme, bæredygtighed, levende kulturarv, community-building, human capital. For overskuelighedens skyld vil jeg sætte fokus på verdensarv, som et grundlæggende begreb i forståelsen af kulturarv, og på kulturel diversitet fordi det begreb har en direkte årsagsvirkning i forhold til den nye opmærksomhed på immateriel kulturarv, som senest har udmøntet sig i en ny konvention. Tilsammen vidner de oplistede stikord imidlertid om, at det normative system via kulturarvsbegrebet er med til at definere globale problemstillinger, som angår så væsentlige ting som samfundets indretning og opbygning, nye forestillinger om udvikling og om menneskelige ressourcer. De afspejler, at der i stigende grad er tale om varditilskrivninger til kulturarv, og at mennesker, helt ned på individniveau, i stigende grad er i fokus. Kulturarv ses ligefrem som et bud på løsningen af en række af nutidens og fremtiden store globale udfordringer:

The idea of cultural heritage as a key element in a new model of sustainable development sees heritage as important in the fight against poverty, and in the protection of the environment, and as a source of capital for local populations as well as a source of pride, social cohesion and collective identity. (Long and Labadi 2010: 12).

Kulturarv betragtes i stigende grad som en central faktor i et nyt udviklingsparadigme og som en form for bæredygtig praksis i forhold til en række sociale, socio-økonomiske og politiske områder. 
I et historisk perspektiv er det nemt at se tendensen. Et hurtigt overblik over konventionerne på kulturbevaringsområdet viser alene i titlerne, og endnu tydeligere hvis man læser begrebsdefinitionerne i konventionsteksterne, at begrebet kulturarv tidligere blev forbundet med noget statisk og først og fremmest materielt. Property afløses af heritage, hvor property ikke nødvendigvis indbefatter forestillingen om at beskytte og overlevere, hvorimod heritage inkluderer forestillingen om noget arvet, som man i sagens natur er forpligtet til at give videre (Prott and O'Keefe 1992: 307). ${ }^{7}$ Distinktionen mellem immovable og movable heritage (fast og flytbar kulturarv), understøtter en materiel forståelse af begrebet. Immovables blev brugt om arkitektur og monumenter i det hele taget over for movables, som kunne flyttes ind i et museum, i et arkiv eller bibliotek (Stanley-Price 2003). Denne skelnen eksisterer stadig (jf. Kulturarvsstyrelsens definition), men spiller en mere underordnet rolle i takt med den øgede bevidsthed om kulturarvsværdier og ikke-materielle dimensioner af kulturarv (Smith 2006. Stanley-Price 2003). ${ }^{8}$ Konserveringsfagligt har en mere nuanceret materialebevidsthed også medvirket til at opbløde begrebslige og faglige skel.

Som det også fremgik af citaterne fra Kulturarvsstyrelsens publikationer, bliver kulturarv i stigende grad forbundet med værdier, der rækker ud over de materielle dimensioner af begrebet, som er udgangspunktet for bevaringstanken. Siden den østrigske kunsthistoriker Alois Riegl i 1903 formulerede en egentligt konserveringsteori i essayet Der moderne Denkmalkultus, sein Wesen und seine Entstehung, var de tidlige bestræbelser på at institutionalisere bevaringstanken forankret i et tilbageskuende og monumentaliserende beva- ringsbegreb (Stenbro 2009: 58-100). Helt op har de internationale normative instrumenter et antikvarisk sigte. ${ }^{9}$

\section{KULTURARV OG CORPORATE RESPONSIBILITY}

I løbet af de seneste 3 årtier ses kulturarv i stigende grad som en lokal, aktiv ressource, der både rummer antikvariske mål (bevaringsinteresser) og politisk-økonomiske mål (udviklings- og markedsrelaterede interesser). Dermed kan kulturarv tjene som udgangspunkt for vedligeholdelse og udvikling af lokalområder (Labadi and Long 2010: 1-16. Starr 2010: 147-170). For få år siden var mantraet oplevelsesøkonomi; senest er nøgleordene identitet og livskvalitet. ${ }^{10}$ Hvis vi vender tilbage til eksemplet med kulturavskommunerne, kan man næsten tale om en markedsføring og branding af de pågældende kommuner ved hjælp af lokale værdier og identitet. Sådanne initiativer ligger tæt på principperne i Corporate Social Responsibility-initiativer (herefter forkortet CSR), som tilstræber at motivere erhvervsinteresser til at prioritere social og miljømæssig ansvarlighed frem for profitmaksimering. Ifølge Starr er der et oplagt sammenfald mellem principperne i kulturbevaring og CSR tanken:

CSR is motivated by a range of factors, in particular ... the ability of an initiative to create shared value, its ability to address the sustainable development agenda, and its ability to provide corporate benefits such as reputation enhancement and increasing visibility ... and social benefits such as establishing identity and pride, promoting social inclusion and regenerating local communities. (Starr 2010: 162163). 


\section{KULTURARVSøKOLOGI}

Denne opfattelse af kulturarv som en nutidig ressource med afgørende betydning for samfundsbygning og samfundsværdier som sammenhængskraft og identitet, tegner konturerne af et nyt begreb, som man kunne kalde kulturarvsøkologi. Økologi er defineret som "videnskaben om forholdene mellem levende organismer og deres omgivelser", ${ }^{11}$ og selv om $ø$ kologi hører under naturvidenskaberne, er det påfaldende, at man meget nemt kan overføre centrale forestillinger fra økologien på kulturbevaringsområdet: Først og fremmest bæredygtighedstanken, som hviler på princippet om diversitet - i naturvidenskaben i form af biodiversitet, på kulturbevaringsområdet i form af kulturel diversitet. Kulturarvens potentiale i forhold til bæredygtig praksis, socialt, økonomisk og politisk, er allerede påpeget af Labadi og Long (2010: 1-16). Økologiens bærende princip om diversitet som forudsætning for bæredygtig udvikling er således at finde i nutidens forståelse af kulturarv.

Uden at anvende begrebet kulturarvsøkologi er Frank Hassard, lektor ved International Institute for Advanced Studies (UK), inde på en lignende tanke (Hassard 2009), idet han påpeger betydningen af Oaxaca deklarationen, der så tidligt som i 1993 taler om "the diversity of cultural identities" (der senere bliver til kulturel diversitet) i forhold til udviklingen af demokratiske samfund. ${ }^{12}$ Hassard kalder den betydning, som tillægges forskellene i kulturelle identiteter, for begyndelsen til "an ecology of human life" (Hassard 2009: 155). Kulturarv og kulturel forskellighed er allerede i Oaxaca deklarationen ikke set som noget, der er overstået og hører fortiden til, men som selve grundlaget for "a pattern of development that places the individual and his values at the center of its concerns" (se note 12) - helt i overensstemmelse med økologiens diversitetsprincip og bæredygtighedstanken.

\section{LEVENDE KULTURARV}

Unescos seneste konvention om immateriel kulturarv er den foreløbige kulmination af en udvidet forståelse af kulturarv i verdensarvsystemet. ${ }^{13}$ Initiativet til at beskytte immateriel kulturarv kan dels ses som en udfordring og nuancering af det monumentaliserende kulturarvsbegreb, og dels som verdensarvsystemets svar på globaliseringens tilsyneladende trussel mod kulturel forskellighed. Motivationen for en særlig beskyttelse af ikke-materiel kulturarv er præciseret $\mathrm{i}$ konventionens indledning, hvor der især henvises til kulturel forskellighed som kilden til immaterial kulturarv og de udfordringer, som globalisering og social forandring udgør både i positiv og negativ retning. ${ }^{14}$ Her er begrebet living heritage centralt. Tanken om personbåren kulturarv (af enkeltindivider eller grupper) har sit udspring i Japans bestræbelser i 1950'erne på at beskytte viden, værdier og færdigheder, som i særlig grad var forbundet med kulturelle praksisser (Kurin 2004: 66-73). I et internationalt perspektiv hviler forestillingen om levende kulturarv på forskellige subjektive værdier (Bortolotto 2010: 98), hvilket i sig selv er vanskeligt foreneligt med en international konvention, hvis formål er at skabe standardiserede rammer for beskyttelse af et givent område. Den nye konvention rummer, måske især i kraft af den tilhørende liste over immateriel kulturarv (se note 21), en række modsigelser. Men ud fra et rent bevaringssynspunkt kan man hævde, at den i kraft af sit sigte på værdier tydeliggør et grundvilkår i forhold til alt, hvad vi betegner som arv, dvs. noget vi mener, vi bør 
passe på, nemlig dette: Hvordan denne arv kan opleves og udtrykkes i nutiden.

Foreløbig har vi sprunget alle mellemregningerne over, men selv i en meget summarisk fremstilling, som vil blive præsenteret i det følgende, tegner sig et klart billede af de ændringer, begrebet kulturarv har gennemløbet, hvilket i høj har en betydning, hvis man vil forstå grundlæggende problemstillinger i forhold til bevaringens teori og praksis, og i forhold til museernes funktion og rolle i samfundet.

\section{KULTURARV SOM IDEOLOGI}

Man kan argumentere for, at verdensarv er det begreb i vores tid, som er mest betegnende for den for-forståelse af kulturarv, som er indbygget i den internationale lovgivning på kulturog naturområdet. ${ }^{15}$ Forestillingen om en verdensarv bliver kraftigt fremført efter 1945, og bygger på en målsætning om fælles ansvar for kultur- og naturarv. Og i kølvandet på hele to verdenskrige inden for blot tre-fire årtier af det 20. århundrede gjaldt det især om at præsentere alternativer til nationalistiske interesser. Man kan ligefrem tale om en kulturarvsideologi, med grundlag i et politisk fredsprojekt efter 2.verdenskrig, som først og fremmest udmøntede sig $\mathrm{i}$ etableringen af $\mathrm{FN}$. Verdensarvkonventionen kan på den baggrund ses som et civilisatorisk projekt nært beslægtet med skabelsen af nationalstaten som civilisatorisk projekt, men med et kosmopolitisk sigte: styrkelsen af forestillingen om verden som ét sted (Turtinen 2006). ${ }^{16} \mathrm{I}$ kraft af globaliseringen, som fik stadig mere gennemslagskraft fra begyndelsen af 1980'erne, har denne universalistiske tanke om verdensarv som et civilisatorisk (freds)projekt fået fornyet aktualitet. Respekten for og forståelsen af andres kultur betragtes stadig, og tilsyneladende med fornyet kraft og aktualitet, som en af de grundlæggende forudsætninger for fred i verden. Det har bl.a. betydet konstruktionen af nye begreber til at udvide forståelsen af kulturarv. Den snart 40 år gamle Verdensarvkonvention kan hævdes at være både eurocentrisk og fokuseret på monumenter, men den kan ikke kun ses som et elitært, civilisatorisk projekt, og i den forstand undertrykkende i kraft af, at stater socialiseres til at acceptere bestemte normer og institutioner (Turtinen 2006). Tværtimod har konventionen og det tilhørende administrative apparat vist sig at være åbent for den kompleksitet, og kulturelle mangfoldighed, som globaliseringen tydeliggør. De begreber, der især har været med til at demonstrere dette - i kraft af at de har været i stand til at rokke ved de etablerede og sejlivede forestillinger om kulturarv i dette system - er: kulturel diversitet og senest immateriel kulturarv.

\section{DIVERSITET OG B/EREDYGTIGHED}

For at gøre en lang historie meget kort, foregik der fra begyndelsen af 1990 'erne en ny-orientering i forhold til nogle af de mest centrale kriterier for bedømmelse af kulturarv i det administrative system, der knytter sig til Verdensarvkonventionen. Autenticitetsbegrebet var især genstand for diskussioner, og med formuleringen af Nara dokumentet (1994) blev kulturarvsbegrebet suppleret med forestillinger, som indtil da ikke havde været taget $\mathrm{i}$ betragtning $i$ udpegningen af emner til Verdensarvlisten, hvor den såkaldte test of authenticity siden 1977 havde opereret med fire faste kriterier : "design, materials, workmanship and setting" for udpegningen af emner til Verdensarvlisten. ${ }^{17} \mathrm{I}$ sin analyse af autenticitetsbegrebet introducerer Sophia Labadi, ph.d. i Cultural Heritage Studies fra Universi- 
12 ty College, London, og rådgiver for UNES$\mathrm{CO}$, et nyt begreb: post-authenticity, idet hun betegner de fire kriterier for definitionen af kulturarv som urealistiske og ligefrem for simulacra - dvs. simulerende en sandhed, som ikke eksisterer (Labadi 2010: 79-80). Med Nara dokumentet blev autenticitet erkendt som et begreb, der defineres forskelligt i forskellige socio-kulturelle kontekster:

All judgements about values attributed to heritage as well as the credibility of related information sources may differ from culture to culture. It is thus not possible to base judgements of value and authenticity on fixed criteria. On the contrary, the respect due to all cultures requires that cultural heritage must be considered and judged within the cultural contexts to which it belongs. ${ }^{18}$

Erkendelsen af kulturers forskellighed, kulturel diversitet, er omdrejningspunktet i den tanke:

The diversity of cultures and heritage in our world is an irreplaceable source of spiritual and intellectual richness for all humankind. The protection and enhancement of cultural and heritage diversity in our world should be actively promoted as an essential aspect of human development. ${ }^{19}$

Dette markerede et vendepunkt i forståelsen af kulturarv, idet verdensarvsystemtet hermed slog fast, at kulturværdier er historisk, socialt, politisk og kulturelt betingede, og kulturel diversitet kom til at spille en helt central rolle herfra. Nara dokumentet blev i 2005 indskrevet $\mathrm{i}$ de operative retningslinier for Verdensarvkonventionen. Den situation kan ses som forudsætningen for de to senest tilkomne UNESCO konventioner, The Convention for the Safeguarding of Intangible Cultural Heritage (2003) og The Convention for the Protection and Promotion of the Diversity of Cultural Expressions (2005). I et historisk perspektiv kan man se dem som en afbalancering af de eurocentriske og monumentaliserende forestillinger om kultur, som havde præget især det foregående århundrede, og som var udgangspunktet for Verdensarvkonventionens forståelse af bevaringsværdig kultur.

I 1995 udgav UNESCO en rapport: Our Creative Diversity. ${ }^{20}$ Det helt centrale tema her var kulturel diversitet. Initiativet var en udløber af Brundtlandkommitteens rapport fra 1987, Our Common Future, som introducerede baredygtighedsprincippet i forhold til miljøet på verdensplan. I Our Creative Diversity blev det samme princip - bæredygtighed - anvendt på kultur i kraft af begrebet kulturel diversitet. Respekten for kulturel diversitet og kulturel pluralisme (ligestilling mellem kulturer) fremstilles i rapporten som selve forudsætningen for bæredygtig udvikling. Det helt afgørende i rapporten er, at udviklingsbegrebet bliver vendt på hovedet. Der er tale om et paradigmeskift, som bl.a. kom til at betyde, at kulturbevaring og kulturgenopbyggende projekter blev et stærkt kort i udviklingsprogrammer i den 3. verden igennem 1990'erne.

\section{KULTURARV OG UDVIKLING}

Hvor tidligere vækst og udvikling var blevet målt i økonomiske vækstparametre i et instrumentelt udviklingsbegreb, så introducerer Our Creative Diversity et nyt parameter: den kulturelle dimension af udvikling, hvor målet er at skabe et bedre liv for mennesker, og hvor økonomi og materiel fremgang blot er midler, ikke mål i sig selv. Det var også en del af forklaringen på, at man op gennem 1990erne så, at selv Verdensbanken igangsatte kulturbeva- 
rende projekter frem for primært profitskabende projekter ud fra den forståelse, at kulturel identitet og ansvar for egen kulturarv og værdier, var selve forudsætningen for at skabe en bæredygtig, dermed også økonomisk, udvikling - et aspekt som allerede Brundtlandrapporten berørte. At kulturarv og kulturel identitet kom i fokus i forhold til udvikling kom især globaliseringen til at tydeliggøre. $\mathrm{Og}$ ved at pege på kulturers forskellighed og vigtigheden af ikke at måle udvikling med de rige landes vækstparametre, blev der også ad den vej åbnet for en bredere forståelse af kulturarv. Det var grundlaget for tanken om kulturarv som et element i bæredygtig udvikling og en ny forståelse af kulturarv ikke kun som noget fortidigt, men som et væsentligt element i en strategi for fremtiden (Labadi and Long: 116). Her ligger forudsætningen for lanceringen af begrebet kulturarvsøkologi.

Den tankegang blev forudsætningen for udvidelsen af verdensarvsystemet med begrebet immateriel kulturarv som en ressource, der bygger på noget fra fortiden, men som rummer forandring og som stadig fornyes i en dynamisk proces:

This intangible cultural heritage, transmitted from generation to generation is constantly recreated by communities and groups in response to their environment, their interaction with nature and their history [økologi tanken], and provides them with a sense of identity and continuity... (The Convetion for the Safeguarding of the Intangible Cultural Heritage, art.2).

De to begreber: kontinuitet og identitet, er kernen i bæredygtighedsprincippet i forhold til kulturarv, og den nye konvention åbner for en ny tilgang til bevaring som en dynamisk, fremadrettet proces med afgørende betydning for fortsat udvikling.
Sammenfattende kan man konstatere, at i takt med globaliseringen har ikke-vestlige opfattelser af kulturarv udfordret den dominerende forestilling, i det internationale institutionelle system, om kulturarv som noget statisk og materielt. Samtidig er der opstået en erkendelse af, at andre kulturer, især afrikanske og asiatiske, ser anderledes på kulturarv end vesten (Kurin 2004).

Denne proces er foregået over de seneste 34 årtier inden for det normative system, som UNESCO danner rammen om. Kulminationen er foreløbig konventionen om immateriel kulturarv, der kan ses som en udfordring af hegemonien på kulturområdet, og som udtryk for en ændret magtbalance i internationale kulturarvssammenhænge, hvis man skulle bruge Turtinens diskursanalytiske tolkning af situationen.

\section{FRA HOLDNING TIL HANDLING}

Sammenfattende kan man se, at Verdensarvkonventionen og den nye konvention om immateriel kulturarv supplerer hinanden med deres forskellige tilgange til forståelsen af kulturarv; men som vi har set, problematiserer de også både forestillingerne om, hvad vi forbinder med begrebet, og måske især, hvad vi gør ved det, vi definerer som kulturarv i bestræbelsen på at bevare det.

Verdensarvkonventionen og den tilhørende liste over kultur- og naturarv ${ }^{21}$ er blevet diskuteret og kritiseret, blandt andet i Laurajane Smith's analyser og i Jan Turtinens begrebs- og institutionsanalytiske undersøgelse af Verdensarvkonventionen, samt i særnummeret i 2004 af UNESCO publikationen Museum International nr. 221/222, for at fastfryse kulturarv, ud fra den overordnede "conserve as found"etos, som er grundlæggende i en vestlig beva- 
14 ringsbevidsthed. Men lige så berettiget en kritik kan rettes mod at definere og opliste immateriel kulturarv, især fordi immateriel kulturarv i højere grad end den materielle er personbåren og hviler på menneskers praksisser. I den forstand betegnes den netop som levende kulturarv, og den er nødvendigvis underlagt forandringer. Det er "det levede liv" som Kulturarvsstyrelsens publikation Kommune kend din kulturarv, der blev citeret tidligere (Kuas 2010: 2-3), også taler om. At indskrive kulturelle praksisser på en liste vil være ensbetydende med at fastfryse de praksisser. Det, der støder sammen her, er forestillingen om kulturarv som noget materielt og forestillingen om kulturarv som dynamiske, levende praksisser.

Den skelnen skaber tydeligvis nogle bevaringsmæssige problemer, som giver anledning til at tænke over, hvad vi forbinder med bevaring. Her er der også nye signaler inden for det internationale system: i 2004 vedtog UNESCO Yamoto Deklarationen, hvis fulde titel siger en del om bestræbelsen - The Yamoto declaration on Integrated Approaches for Safeguarding Tangible and Intangible Cultural Heritage. Deklarationen repræsenterer en udvikling i bevaringspraksis på kulturområdet, som er en konsekvens af en forståelse, som ikke skelner så hårdt mellem den materielle og ikke-materielle dimension af kulturarvsbegrebet; den forsøger faktisk at forene de to opfattelser. $\mathrm{Og}$ hvis man på det grundlag tænker over konsekvenserne for bevaringsbegrebet, så giver bestræbelser på at bevare materiel såvel som immateriel kulturarv, begge båret af menneskers indoptagelse og videreførelse af den, kun mening, hvis man opfatter bevaring ikke som en fastfrysning, men som en fremadrettet proces, som giver plads til forandring $\mathrm{i}$ forhold til hvad vi forbinder med kulturarv / eller det vi bevarer, og hvordan vi kan opleve, udtrykke og bruge det, vi har bevaret i nutiden og $\mathrm{i}$ fremtiden.

I forhold til de tekniske og praktiske aspekter af bevaring, i form af konservering og restaurering og de tekniske processer, der er involveret dér, er man nødt til at forholde sig til hvad det er, vi mener vi har arvet, som denne artikel har forsøgt at reflektere over, og hvordan vi bevarer, og måske allervigtigst hvorfor? Laurajane Smith har nogle overvejelser om, hvad bevaring går ud på, som er nyttige at have med i bagagen som arkitekt eller som konservator eller som kulturarbejder i det hele taget, og uanset faglig specialisering. Citatet hænger godt sammen med hendes påstand, som blev citeret $\mathrm{i}$ indledningen, om at kulturarv ikke findes som et selvforklarende begreb. Det findes kun i kraft af de betydningstilskrivninger, mennesker foretager. Så hvad er det egentlig, bevaringsbetræbelser går ud på:

It is value and meaning that is the real subject of heritage preservation and management processes, and as such all heritage is 'intangible', whether these values or meanings are symbolized by a physical site, place, landscape or other physical representation, or are represented within the performances of languages, dance, oral histories or other forms of intangible heritage. (Smith 2006: 56).

Den definition stemmer tilsyneladende godt overens med min analyse af teksterne i denne artikel. Bevaring, både i museologisk betydning og i teknisk-praktisk betydning, kan på den baggrund ses som en socialt og kulturelt betinget praksis, hvis mål er at sikre "value and meaning" og dermed sikre og styrke kontinuitet, identitet og livskvalitet både for den enkelte og for samfundet. I det historiske perspektiv er kulturarvsdiskursen kommet et 
langt skridt videre fra distinktionen mellem property og heritage og mellem movable og immovable. Distinktionen mellem tangible og intangible har tydeliggjort nogle spørgsmål, som især har drejet sig om de krav, man kan stille til institutionerne og til de faglige specialiseringer i forhold til bevaring af kulturarv. Er der behov for en nyorientering af eksisterende uddannelser i retning af større tværfaglighed, som afspejler opblødningen af distinktionen mellem fast og flytbar og mellem materiel og immateriel kulturarv? Er der behov for nye typer af institutioner?

\section{KONKLUSION}

For 20 år siden beskrev Tomislav Sola, professor i museologi ved Universitetet i Zagreb, i sin teori for en ny museologi en vision for fremtidens museer, som han forudså som "... a mixture of documentation centre, traditional museum, library, theatre, creative workship and leisure facility."(Sola 1992: 4). Det var især museets sociale funktioner der optog ham. ${ }^{22}$

I lyset af de nye udfordringer, som nutidens opfattelse af kulturarv og bevaringsproblematikker stiller over for både museer og kulturinstitutioner, kan man sige, at hans vision stadig holder og tilmed er bestyrket:

The nonsense of division between movable and immovable heritage ${ }^{23}$ will disappear, when confronted with free action. What will matter will be entity (the identity in its broadest possible interpretation and context) that needs continuation. Heritage institutions will be more and more the core of action trying to make things happen where they are needed ... (Sola 1992: 4)

I definitionen af museet som samfundsinstitu- tion i ICOMs seneste revision af de museumsetiske regler, er "material evidence" erstattet med "tangible and intangible evidence"(note 1), ligesom museernes forpligtelse til at samarbejde med det omgivende samfund, den lokalitet eller de befolkningsgrupper, de betjener, er blevet styrket (økologitanken). ${ }^{24}$ Det åbner for nye perspektiver for museernes rolle og funktion i samfundet. Præcis hvilke, er det endnu for tidligt at sige, ligesom diskussionen af, hvad immateriel kulturarv i praksis dækker, langt fra er slut. Det ser umiddelbart ud, som om ICOMs seneste definition godt kan holde til Solas visioner.

Som nævnt i indledningen var de konserveringsfaglige udfordringer $\mathrm{i}$ fokus $\mathrm{i}$ denne undersøgelse. På de kulturbevarende institutioner er formidling og kommunikation mellem forskellige forskergrupper og med institutionernes brugere og besøgende på vej til at spille en stadig større rolle. For konserveringsfaget er det tydeligt, at aspekter af konservering i de senere år har indtaget en stadig mere synlig rolle i denne sammenhæng, især i forbindelse med konkrete konserverings/restaureringsprojekter, men også ved undersøgelser og analyser af kulturarvsgenstande. Som udgangspunkt var der tale om åbne værksteder på de store, kulturbevarende statslige institutioner, og særudstillinger med tekniskkunsthistorisk forskning som grundlag. ${ }^{25}$ I takt hermed er der opstået et fokus på konserveringsfagets store formidlingspotentiale, som inden for de seneste år især har resulteret i en styrkelse af den digitale formidling, dels af konserveringsrelaterede problemstillinger i forhold til konkrete værker, dels i forhold til teknisk kunsthistorie, hvor konserveringsfagets undersøgelses- og diagnosticeringsteknikker benyttes i en større sammenhæng end den rent konserverings/restaureringsmæssige. Det 
16 digitale vidensmedium er særligt interessant i forhold til konserveringsvidenskaben, idet 'viden' i konserveringssammenhæng i høj grad beror på visuelle processer og undersøgelsesmetoder og -teknikker, frem for det trykte ord. Muligvis er dette en del af forklaringen på succesen med visuel og taktil formidling af konserveringsfaglige problemstillinger, som har potentiale til at ændre museernes forsknings- og formidlingspraksis.

Der er grund til at forvente, at nye begrebsdannelser skaber nye institutioner. Det var tydeligt fra 1950'erne og frem, hvor institutionaliseringen af kulturarvsområdet tog form samtidig med etableringen af en række uddannelser, som understøttede bevaring af materiel kulturarv. De nye begrebsdannelser, der har været under luppen her, skaber grundlag for en nyorientering af de faglige specialiseringer, der sigter på kulturbevaring i alle dens aspekter.

Måske kan man nøjes med at konkludere, at med de udvidede forestillinger om, at "all heritage is intangible" (Smith 2006: 56), er forudsætningerne tilsyneladende bedre end nogensinde, for at synliggøre kulturarv og for at bruge kulturarvsressourcer til at styrke identitet, kontinuitet og livskvalitet for den enkelte og for samfundet.

\section{Indleveret september 2011.}

\section{NOTER}

1. I den seneste revision (2006) af ICOMs museumsetiske regler er definitionen af et museum blevet ændret fra den forrige revision (2002): ... material evidence ...” er erstattet af "... tangible and intangible evidence ...," så et museum senest er defineret således: "A museum is a non-profit making permanent institution in the service of society and of its development, open to the public, which acquires, conserves, researches, communicates and exhibits, for purposes of study, education and enjoyment, the tangible and intangible evidence of people and their environment." http://icom.museum/what-we-do/professional-standards/code-of-ethics/glossary.html\# sommairecontent

2. Kulturarvsstyrelsen, etableret 2001, er den styrelse under Kulturministeriet, som forvalter kulturarv i Danmark. Fra 1.1.2012 blev Kulturarvsstyrelsen omdøbt til Kulturstyrelsen.

3. Strukturreformen blev vedtaget i 2005 af den borgerlige regering, og trådte i kraft i 2007. Den gik ud på at ændre opgavefordelingen i den offentlige sektor i Danmark. Antallet af kommuner blev mere end halveret, og amterne blev nedlagt. På kulturområdet kom det blandt andet til at betyde, at kommunerne blev den største forvalter af kulturarv i Danmark.

4. Dk har ratificeret en række konventioner på kulturområdet (dels i Europarådets regi dels i UNESCOs regi). For detaljer se: http://www.kulturarv.dk/om-os/love-og-bekendtgoerelser/internationale-konventioner/(Konventionen om immateriel kulturarv figurerer endnu ikke på Kuas hjemmeside. Den blev approberet, hvilket er et trin før ratificering, 30.10.2009).

5. Guidelines to the Burra Charter: Cultural Significance, 2.5.11 http://australia.icomos.org/wp-content/uploads/BURRA_CHARTER.pdf

6. The Nara Document on Authenticity in Relation to the World Heritage Convention. http://whc. unesco.org/uploads/events/documents/event443-1.pdf

7. Begrebet ejendom kan dog godt komme ind under arv, som det afspejles i nogle af UNESCOs konventioner blandt andre 1954 og 1970.

8. I det normative system har der i de senere år også foregået en diskussion af distinktionen mellem kultur- og naturarv. Tendensen er henimod en 
sammensmeltning af de to begreber, idet kulturog naturarv i The Operational Guidelines for the Implementation of the WHC efter revisionen i februar 2005 bedømmes efter de samme kriterier (\$77 og 87).

9. Dog skal det understreges, at de løbende revisioner af The Operational Guidelines for the Implementation of the World Heritage Convention, som er det instrument, der aktualiserer og gør den nu 40 år gamle Verdensarvkonvention brugbar, tager højde for forandrede forestillinger om kulturarvsværdier.

10. Livskvalitet genereret i kraft af kulturarv understreges igen og igen i regeringens arkitekturpolitiske program Arkitekturnation Danmark (2007).

11. Den store danske encyclopadi. Bind 20. Gyldendal 2001.

12. Den nævnte passage fra Oaxaca deklarationen lyder som følger: "The reassertion of the diversity of cultural identities and their consolidation are bulwarks against the danger of a technological society, which succumbs because it is powerless to achieve that democracy towards which mankind strives, because it is incapable of creating efficient instruments to attain a pattern of development that places the individual and his values at the center of its concerns. Identities, in short, that propel history, that are not frozen legacies but living syntheses, perpetually changing, thriving on inner differences, admitting and reworking contributions from outside." http://www.icomos.org/unesco/oaxaca.html

13. The Convention for the Safeguarding of the intangible Cultural Heritage. Konventionen blev vedtaget på UNESCOs 32. generalforsamling i 2003 med ikrafttræden 2006 (Danmark approberede konventionen i oktober 2009).

14. "... the conditions they [globalisation and social transformation] create for renewed dialogue among communities also give rise, as does the phenomenon of intolerance, to grave threats of deterioration, disappearance and destruction of the intangible cultural heritage in particular owing to a lack of resources for safeguarding such heritage." (The Convention for the Safeguarding of the Intangible Cultural Heritage. Preamble. http://unesdoc.unesco.org/images/0013/001325/ 132540e.pdf).

15. Verdensarvkonventionen dækker som bekendt både kultur- og naturarv, og eftersom den er ratificeret af 187 ud af ca. 200 stater på verdensplan, må den betragtes som et meget virksomt instrument på kulturbevaringsområdet.

16. For en ordens skyld bør det nævnes, at universalistiske ideer om menneskehedens fælles kultur havde været udtrykt tidligere, faktisk helt tilbage i 1700-tallet, men ikke på internationalt plan og slet ikke på en sådan institutionaliseret måde som efter 2.verdenskrig.

17. Operational Guidelines for the Implementation of the WHC, paragraph $79 \mathrm{http} / / /$ whc.unesco. org/archive/opguide08-en.pdf. Siden 2005 henvises der for autenticitetskriterier til Nara dokumentet, som er vedhæftet som appendix til de operative retningslinier. Forud for 2005 var autenticitet defineret $\mathrm{i}$ forhold til at et nomineret emne til WHL skulle "... meet the test of authenticity in design, material, workmanship or setting" (2002, paragrapg 24, bi) (http://whc.unesco. org/archive/opguide02.pdf).

18. The Nara Document on Authenticity in Relation to the World Heritage Convention $₫ 11$.

19. ibid. $\$ 5$.

20. Our Creative Diversity. Report of the World Commission on Culture and Development. UNESCO 1995.

21. Der knytter sig lister over kulturarv under særlig beskyttelse af verdenssamfundet både til Verdensarvkonventionen og til den nye Konvention om immateriel kulturarv - henholdsvis: The World Heritage List, samt listen over særligt truet verdensarv: The List of World Heritage in Danger, 
http://whc.unesco.org/en/list og The Representative List of the Intangible Cultural Heritage of Humanity, med en tilsvarende liste over særligt udsat immateriel kulturarv: The List of Intangible Cultural Heritage in Need of Urgent Safeguarding: http://www.unesco.org/culture/ich/index. php?lg=en\&pg=00011.

22. Sola beskriver i A contribution to understanding of museums: Why would the museums count? (http://dzs.ffzg.hr/text/sola-contribution.htm) (u.å), museet således: "As a wise social device working to the advantage of its community, it adapts the community to the changing conditions in its surroundings and in itself, creating thus viable preconditions for its prosperity". (loc cit. Afsnittet: The True Nature of Museums).

23. - og senest må vi også tilføje :"...tangible and intangible...”.

24. "Museums have an important duty to develop their educational role and attract wider audiences from the community, locality or group they serve. Interaction with the constituent community and promotion of their heritage is an integral part of the educational role of the museum" (principle 4, ICOM Code of Ethics) http://icom.museum/fileadmin/user_upload/pdf/Codes/code2006_eng. pdf

25. Eksempelvis Rembrandt udstillingen på Statens Museum for Kunst i 2006.

\section{LITTERATUR}

Arkitekturnation Danmark - rammer for liv, rammer for vakst. Kulturministeriet $2007 \mathrm{http}: / / \mathrm{kum} . \mathrm{dk} /$ Servicemenu/Publikationer/2007/Arkitekturnation-Danmark/ (acc.18.01.11).

Bortolotto, Chiara: Globalising intangible cultural heritage ? Between international arenas and local appropriations. Heritage and Globalisation, eds. Sophia Labadi and Colin Long, Routledge, 2010 (kap.5, 97-114).

The Burra Charter (1979 revideret 1999) http://aus-
tralia.icomos.org/wp-content/uploads/BURRA_CHARTER.pdf (acc.20.01.11).

The Convention for the Safeguarding of the Intangible Cultural Heritage (2003, ikrafttræden 2006) http://unesdoc.unesco.org/images/0013/001325/132540e.pdf (acc. 26.01.11).

The Convention for the Protection of the World Cultural and natural Heritage (1972) http://whc.unesco.org/en/conventiontext (acc.26.01.11).

Convention on the Protection and Promotion of the Diversity of Cultural Expressions (2005, ikrafttræden 2007) http://www.unesco.org/new/en/ unesco/themes/2005-convention/the-convention (acc.26.01.11).

The Declaration of Oaxaca. http://www.icomos.org/ unesco/oaxaca.html (acc.18.01.11).

Hall, Stuart: The Centrality of Culture. Notes on the Cultural Revolutions of Our Time. Media and Cultural Regulations. Ed. Kenneth Thompson. London, Sage Pulications 1997, 207-238.

Hassard, Frank: Towards a new vision of restoration in the context of global change. Journal of the Institute of Conservation, Vol 32, no.2, September 2009, 149-163.

ICOM Code of Ethics for Museums (2004) http://icom.museum/what-we-do/professionalstandards/code-of-ethics/glossary.html\#sommairecontent (acc.28.02.11).

Jensen, Bernard Eric: Kulturarv - et identitetspolitisk konfliktfelt. Gads Forlag 2008.

Kulturarvsstyrelsen og Realdania: Kulturarv - en verdifuld resource for kommunerne. En analyse af danskernes holdninger til kulturarv. (September 2005) http://www.kulturarv.dk/fileadmin/ user_upload/kulturarv/publikationer/emneopdelt/kommuner/kulturarvsanalyse/kulturarvsamlet.pdf (acc.21-01.11).

Kulturarvsstyrelsen og Realdania: Kulturarven - et aktiv. Anbefalinger fra 4 kulturarvskommuner (2.12.2007) http://www.kulturarv.dk/filead- 
min/user_upload/kulturarv/publikationer/emneopdelt/kommuner/Kulturarvskommuner/Kulturarven_et_aktiv.pdf (acc.21.01.11).

Kulturarvsstyrelsen og Realdania: Kommune - kend din kulturarv. (1.12.2010) http://www.kulturarv.dk/fileadmin/user_upload/kulturarv/publikationer/emneopdelt/kommuner/Kulturarvskommuner/Kommune_-_kend_din_kulturarv.pdf (acc.21.01.11).

Kurin, Richard:Safeguarding Intangible Cultural Heritage in the 2003 UNESCO Convention: a critical appraisal. Museum International, nr. 221222, May 2004 (66-76).

Labadi, Sophia : World Heritage, authenticity and post-authenticity. Heritage and Globalisation, eds. Sophia Labady and Colin Long, Routledge, 2010 (kap.3, 66-84).

Long, Colin and Sophia Labadi: Introduction to Heritage and Globalisation. eds. Sophia Labady and Colin Long, Routledge, 2010 (1-16).

The Nara Document on Authenticity in Relation to the World Heritage Convention. http://whc.unesco.org/uploads/events/documents/event-443-1.pdf (acc.20.01.11).

Our Creative Diversity. Report of the World Commission on Culture and Development. UNESCO 1995.

Prot, L.V and P.O'Keefe: Cultural Heritage and Cultural Property. Instrnational Journal of Culturalprotperty, 1992, 307-320.

Smith, Laurajane: Uses of Heritage. Routledge 2006

Sola, Tomislav: The Future of Museums and the Role of Museology. http://dzs.ffzg.hr/text/

Sola_1992.pdf

Sola, Tomislav: A Contribution to Understanding of Museums: Why would the Museums Count? (u.å) http://dzs.ffzg.hr/text/sola-contribution.htm Stanley-Price, Nicolas : Movable. Immovable. A Historic Distinction and its Consequences. Leicester Conference : Conservation of historic buildings and their contents. 2003, 14-27.
Starr, Fiona: The business of heritage and the private sector. Heritage and Globalisation, eds. Sophia Labadi and Colin Long, Routledge, 2010, 147 169.

Stenbro, Rikke: Bevaringsprocesser - perspektiver på arkitektur i forandring. Upubliceret ph.d. afhandling, 2009. Arkitektskolen i Aarhus, Institut for Arkitektonisk Kulturarv.

Turtinen, Jan: Världsarvets villkor; interessen, forrhandlingar och bruk i international politik. Acta Universitatis Stockholmiensis; 1. Stockholm 2006.

*Beate Knuth Federspiel. Associate professor. Field of specialization: Heritage preservation.

Address: Det Kongelige Danske Kunstakademis Skoler for Arkitektur, Design og Konservering. Konservatorskolen, Esplanaden 34,

DK-1263 København K

\section{E-mail:bkf@kadk.dk}

Web: www.kons.dk 